\title{
The Opinions of Field Experts on the Usability of Internet-of-Things Technology in Open and Distance Learning Environments
}

\author{
Hakan Altınpulluk, Anadolu University, Turkey \\ (iD) https://orcid.org/0000-0003-4701-1949 \\ Hakan Kilinc, Anadolu University, Turkey* \\ (iD https://orcid.org/0000-0002-4301-1370
}

\begin{abstract}
This study aimed to determine the usability of the internet of things technology in open and distance learning environments. In this context, the phenomenology method was used in order to get the opinions of field experts. The criterion sampling method, which is one of the purposeful sampling methods, was used in determining the participants. As a criterion, it is taken into account that the participants are experts in the field of open and distance learning. In this context, eight field experts contributed to the study. The findings obtained at the end of the study clarify how internet of things technology can be used in traditional face-to-face learning environments and open and distance learning environments, what benefits it can provide, what are its limitations, its future usage trends, and how it can be used outside of learning environments.
\end{abstract}

\section{KEYWORDS}

Field Expert, Internet of Things, Open and Distance Learning, Phenomenology, Usability

\section{INTRODUCTION}

Internet of Things technology has become one of the most popular technological concepts, especially with the rapid developments in the internet field. The Internet of Things (IoT) is a global network of devices that can be accessed and controlled online that detect data from environments in domestic, industrial, and scientific contexts (Davies et al., 2020). IoT is the process of equipping machines and objects with sensors, allowing them to communicate with each other via the Internet or Local Area Network (LAN) (Kılınç, 2020). As the Internet changes global human-to-human contact, IoT aims to innovate in human-to-machine and machine-to-machine communication. Advances in cloud computing, integrated networks, high-speed internet, and 4G / 5G internet protocols have enabled the internet to penetrate almost every corner of our physical space. This means that more and more objects can be integrated over the internet (Qazi, 2019).

According to a study by Juniper Research (2020), the number of IoT devices connected to each other "almost tripled" from 13.4 billion in 2015 to 38 billion in 2020. According to another research 
report called "IoT in Education Market" by Markets and Markets (2018), the global market size of IoT in education is expected to increase from $\$ 4.8$ billion in 2018 to $\$ 11.3$ billion by 2023 .

Another area where IoT technology has started to become popular in recent years has been the field of education (Altınpulluk, 2018; Korzun \& Bogoiavlenskaia, 2020; Shaikh et al., 2019). It is seen that IoT technology has the potential to transform education by profoundly changing the way educational institutions collect data, create interactive interfaces, and automate processes (ALE, 2018). According to An, Wang, and Wang (2018), when IoT technology is used in education, it enriches assessment processes, guidance, and learning resources. It also supports mobile and ubiquitous learning and positively influences educational management practices such as equipment management, school safety management, and digital campus construction.

According to ALE (2018), IoT is a new paradigm in education when combined with technologies such as user mobility and data analytics. Besides, It can create new ways for students to learn by supporting more personalized and dynamic learning experiences, such as interactive digital textbooks and game-based learning. However, IoT that increases the efficiency of the learning process with high performance and low energy (Tutorials Point, 2020), has the potential to help students, teachers and administrators interact with and connect with technology and devices in classroom environments, helping to improve learning experiences, improve educational outcomes, and lower costs.

In open and distance learning processes, there are some studies in which online education classes are structured using the Internet of Things technology. In the study carried out by Yang and $\mathrm{Yu}$ (2016), it was concluded that using sensors and embedded technologies, IoT increased the academic performance of students and the teaching abilities of teachers. Tobarra et al. (2019) created an approach using Web of Things platforms to develop distance learning scenarios in the Computer Science discipline. Bao (2016) found that more reliable assessment and evaluation processes are carried out by using the Internet of Things technology in the online learning assessment system. With a course structure called "My Digital Life" at British Open University, a design centered on student experiences was prepared by placing the Introduction to Computer Science curriculum on the basis of the Internet of Things, and many activities in this course, experienced by 2000 students, were carried out on the basis of collaborative programming (Kortuem et al., 2013). Deng and Sang (2010), based on the need to abandon traditional distance education methods, developed an interactive Internet of Things platform. In this context, online telescope control was given to students in primary and secondary schools in Wuxi city, and the opportunity to observe space was provided remotely. Besides, students were allowed to download the pictures they observed, share the data with other students, and collaborate in the learning process.

In summary, it is understood that open and distance learning applications that are directly affected by innovative technologies such as IoT will be used extensively in the future. In the related literature, although there are some studies in which IoT technology is used in various ways in the field of education (Abbasy \& Quesada, 2017; Mertala, 2020; Yeh et al., 2020), there are no studies based on qualitative methods, especially in which the opinions of field experts in the field of open and distance learning are examined. It is thought that this study, which includes the usability of IoT technology in traditional learning environments and open and distance learning environments, what benefits or limitations it may bring if used, future usage trends and uses outside of learning environments, can reveal the current situation, contribute to the literature and shed light on future studies. Based on this point, the aim of the study is to determine the usability of IoT technology in open and distance learning environments according to the opinions of field experts. At this point, it is of great importance to examine the opinions of open and distance learning field experts. In this context, answers to the following research questions are sought:

- How can IoT be used in traditional learning environments?

- How can IoT be used in open and distance learning (with remote access)?

- What are the benefits of IoT technology for open and distance learning environments? 
- What are the limitations of IoT technology in open and distance learning environments?

- What are the future usage trends of IoT technology in learning environments?

- What are the possibilities of the use of IoT technology outside of learning environments?

\section{METHOD}

In this study, the phenomenology method was used in order to get the opinions of experts in the field of open and distance learning on the internet of things technology. Phenomenology pattern, a research design that focuses on phenomena that we are aware of but do not have an in-depth and detailed understanding, is an inquiry strategy in which the researcher tries to define the essence of human experiences about a phenomenon explained by the participants (Creswell, 2003).

\section{Study Group}

In qualitative research, purposeful sampling is preferred over random sampling, as it is recommended to keep the sample group small in order to investigate the sample in depth (Miles \& Huberman, 1994). In order to be suitable for the purpose of the study, the criterion sampling method, which is one of the purposeful sampling methods, was preferred. The basic understanding of the criteria sampling method is to study all situations that meet a predetermined set of criteria. At this point, a set of previously prepared criteria can be used, as well as developed by the researcher (Yıldırım \& Şimşek, 2011). In this study, the criteria for participants to be open and distance learning experts were taken into account. In this context, the demographic information of the experts who contributed to the study are shown in Table 1 .

\section{Table 1. Demographic information of the participants}

\begin{tabular}{|l|l|l|l|}
\hline Participant & Age & Gender & Seniority (Year) \\
\hline A1 & 55 & Female & 35 \\
\hline A2 & 45 & Male & 30 \\
\hline A3 & 68 & Male & 45 \\
\hline A4 & 57 & Male & 34 \\
\hline A5 & 41 & Female & 17 \\
\hline A6 & 38 & Female & 14 \\
\hline A7 & 41 & Male & 4 \\
\hline A8 & 38 & Male & 15 \\
\hline
\end{tabular}

\section{Data Collection Tool}

Structured interview questions were directed to open and distance learning experts in order to get their views on the internet of things technology. Before the interviews, the content validity of the structured interview form was obtained by obtaining the opinions of three experts working on qualitative research methods and the final version was given. The structured interview form, which was finalized in line with the opinions of field experts, was created through Google Docs. The interview form consists of 6 open-ended questions. Open-ended questions were prepared in line with the research questions prepared within the scope of the research purpose. 


\section{Data Analysis}

Content analysis method was used to analyze the data. The main purpose of content analysis is to reach the concepts and relationships that can explain the collected data. For this purpose, the collected data must first be conceptualized, then organized in a logical manner according to the emerging concepts and the themes explaining the data must be determined accordingly (Yıldırım ve Şimşek, 2011). Content analysis to be carried out within the scope of the study was carried out using NVIVO 12 qualitative data analysis program. The codes were determined as a result of the content analysis of the raw data obtained from the interviews. The codes obtained are presented in the findings section of the study.

\section{FINDINGS}

The findings obtained in the light of the questions asked to the participants within the scope of this study are given below.

\section{Usability of loT Technology in Traditional Learning Environments}

The first question asked to the participants within the scope of the study was on how IoT technology can be used in traditional learning environments. The findings obtained in this context are shown in Figure 1.

\section{Figure 1. Usability of loT technology in traditional learning environments}

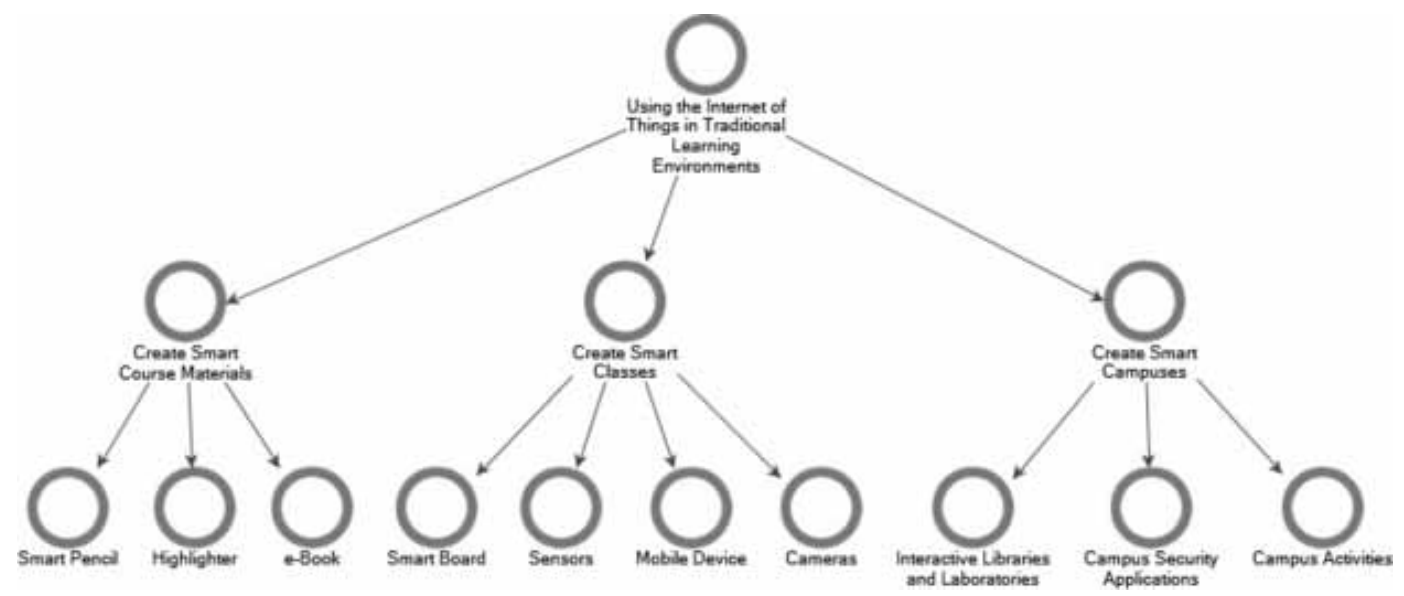

The sub-themes obtained under this main theme were collected in three categories. These categories are; Create Smart Course Materials, Create Smart Classes and Create Smart Campuses. Sub-themes obtained under these categories are shown in Figure 1.

The opinions obtained from the participants regarding the use of IoT technology in traditional learning environments are summarized as follows;

"In traditional learning, it can be used for both course materials and student information." A2 "I think the foundations of IoT were laid in traditional learning environments. Simultaneous display of the presentation opened on the smartboard from the student's tablet and the teacher's smartphone can be a good example for this. "A4 
"Since many objects from the student's athlete to shoelaces will produce information with wearable technologies, especially in science and sports, such technologies can be used a lot." Al

"Smart classes can perceive students and transmit the records of the lessons taught in the classroom to the students. Thus, seamless learning designs can be realized. "A8

"It can be used in the management of students and faculty members." A7

"The course materials can be up-to-date and interactive, learners can also produce materials, and the course materials are made smart." A3

\section{Usability of IoT Technology in Open and Distance Learning Environments}

The second question asked to the participants within the scope of the study was on how IoT technology can be used in open and distance learning environments. The findings obtained in this context are shown in Figure 2.

Figure 2. Usability of loT technology in open and distance learning environments

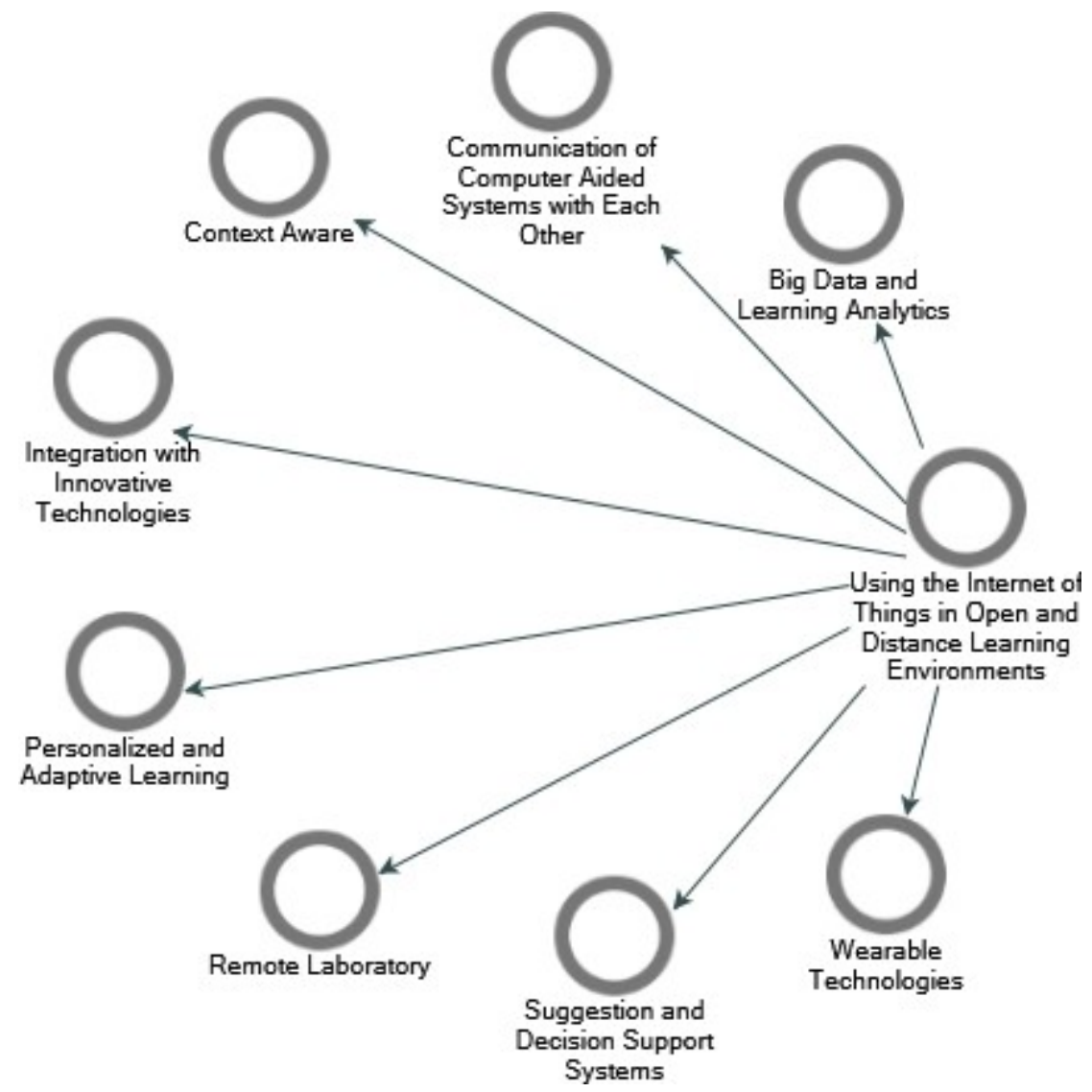

The sub-themes obtained under this main theme were collected in eight categories. These categories are; Big Data and Learning Analytics, Communication of Computer Aided Systems with Each Other, Context-Aware, Integration with Innovative Technologies, Personalized and Adaptive Learning, Remote Laboratory, Suggestion and Decision Support Systems and Wearable Technologies. 
The opinions obtained from the participants regarding the use of IoT technology in open and distance learning environments are summarized as follows;

"If the learner has devices connected with these objects outside the classroom, I think it will be particularly effective for individualized and adaptive learning when he / she will follow the learner's development in-class and out-of-class.” A1

"Data on learners' learning processes can create meaningful data especially for the guiding roles of teachers." A5

"I think it can be used effectively in the design of individualized and adaptive learning processes." A6

"With which type of devices learners carry out their learning activities, what kind of content they prefer, how long they consume these contents, various success criteria can be collected in the management system and appropriate learning processes can be offered to learners or alternative suggestion systems can be offered." A8

"Another example could be STEM education. Continuous performance monitoring can be done in the interactions that the student will have with various interfaces." A2

"It must be integrated with blockchain-based technologies." A4

\section{Benefits of loT Technology for Open and Distance Learning Environments}

The third question asked to the participants within the scope of the study was on what benefits IoT technology will provide for open and distance learning environments. The findings obtained in this context are shown in figure 3.

The sub-themes obtained under this main theme were grouped into eleven categories. These categories and their subcategories are shown in Figure 3. The opinions obtained from the participants regarding the benefits of IoT technology in open and distance learning environments are summarized as follows;

"Uninterrupted learning experiences can be enabled by strengthening the communication between virtual campuses and physical campuses of universities that provide education in dual mode. Providing continuous learning processes will result in meaningful learning experiences."A7

"Smart televisions, smartphones, digital assistants, smartwatches can provide uninterrupted access to learning content through all these technologies, and students can access information and access environments where they can ask questions."A4

"More efficient learning environments can be created by analyzing the data produced from all these objects."A6

"What kind of content will be offered to students enrolled in a program can be achieved through this technology."A5

"It provides the learner with the necessary infrastructure to make sense of learning and to manage learning." $A 3$

"It is easy to follow the participation status of students in learning environments." A2

"It allows you to interact more comfortably with the whole world. Provides ease."Al

\section{Limitations of IoT Technology in Open and Distance Learning Environments}

The fourth question asked to the participants within the scope of the study was about the limitations of IoT technology in open and distance learning environments. The findings obtained in this context are shown in figure 4.

The sub-themes obtained under this main theme were grouped into six categories. These categories are shown in figure 4.

The opinions obtained from the participants regarding the limitations of IoT technology in open and distance learning environments are summarized as follows; 
Figure 3. The Benefits of loT technology for open and distance learning environments

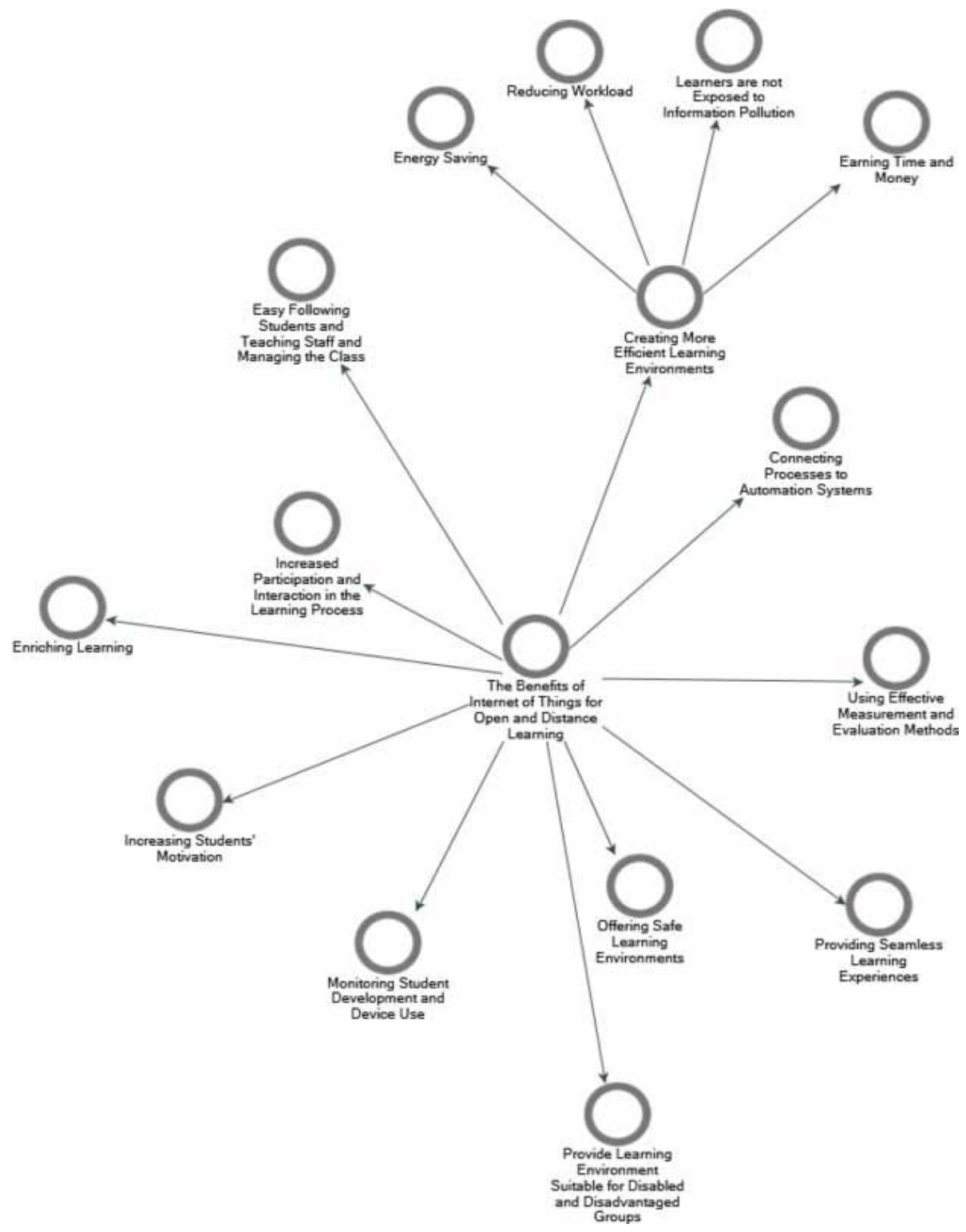

"The most important point to be considered is the protection of personal data and its use without harming the privacy of individuals. Ethical processes should be developed in parallel with the technological infrastructure."A7

"Internet infrastructure must be very strong. In this case, it can be seen as a limitation."A6

"If we try to install a GSM card on every device in a house, the cost of using the device, and the cost of the internet increases considerably. The use of electrical energy will also increase."A3

"Designing the Internet of Things technology to recognize and monitor students at all times will raise important privacy issues."Al

"Data security will be very important in this process."A5 
Figure 4. Limitations of the internet of things technology in open and distance learning environments

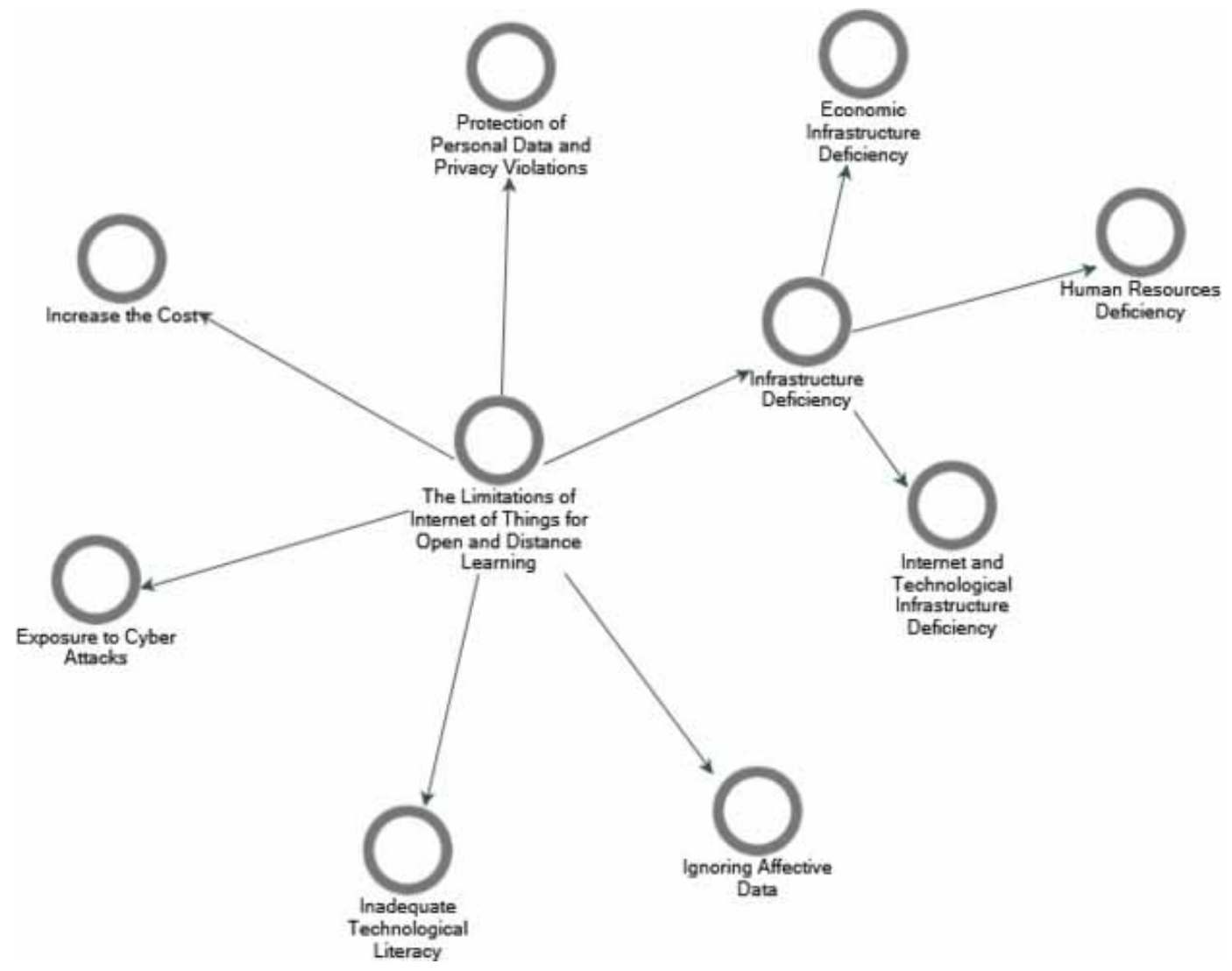

"The use of this technology can pose ethical problems for learners. It should be clearly stated to the learners in advance how and by whom the data will be used."A8

"The process carried out through IoT completely reflects the processes in our communication with the device. Not taking into account other processes can be seen as a limitation."A4

\section{Future Usage Trends of IoT Technology in Learning Environments}

The fifth question asked to the participants within the scope of the study was on the future usage trends of IoT technology in learning environments. The findings obtained in this context are shown in Figure 5.

The sub-themes obtained under this main theme were collected in nine categories. These categories are shown in figure 5.

The opinions obtained from the participants within the scope of the future usage trends of IoT technology in learning environments are summarized as follows;

“Turning physical campuses into a living space beyond just being a place where education is given.”A5 "Thanks to the lenses, headphones, and gloves that work integrated into our body, we will be able to see farther, distinguish different sounds, and have more feelings."A3

"The production of smart learning objects together with IoT technology will positively affect learning environments."A4

"It will enable people to be highly interactive with each other."A8 
Figure 5. Future usage trends of iot technology in learning environments

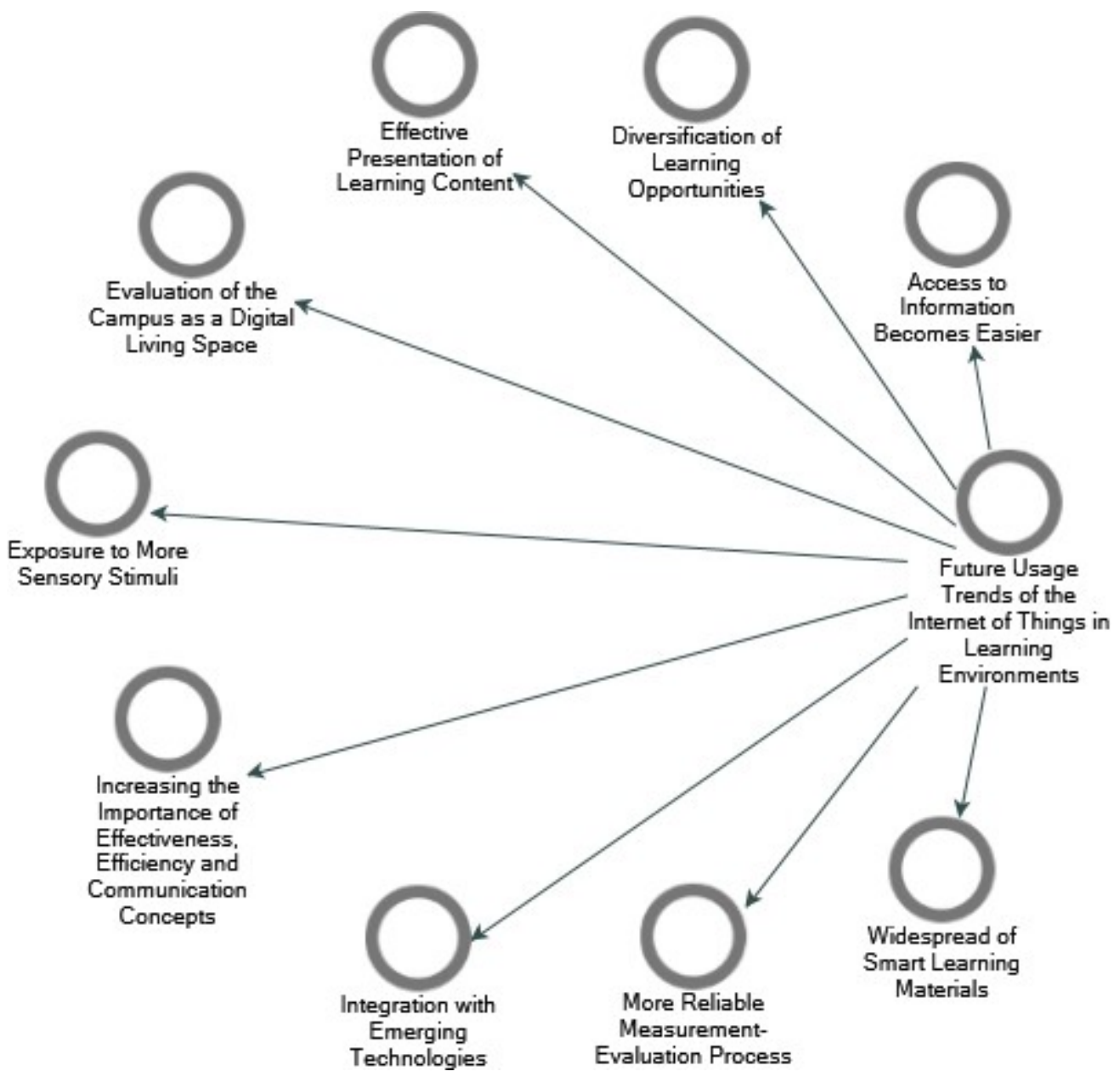

\section{Using loT Technology Outside of Learning Environments}

The last question asked to the participants within the scope of the study was about the use of IoT technology outside of learning environments. The findings obtained in this context are shown in figure 6 .

The sub-themes obtained under this main theme were grouped into four categories. These categories are listed as "Creating Smart Cities, Follow-up and Control of Individuals in Pandemic and Disaster Periods, It is a Facilitating Technology in all Areas of Life and Working with the Robotic Field". These categories are shown in figure 6.

The opinions obtained from the participants regarding the limitations of IoT technology in open and distance learning environments are summarized as follows. 


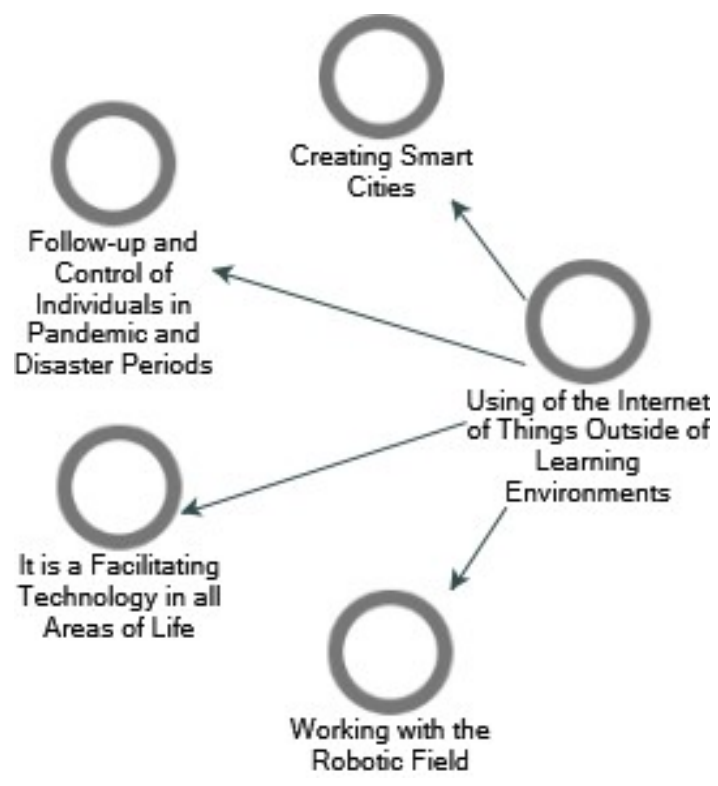

"Smart campuses supported by IoT can also be integrated with Smart Cities supported by IoT, enabling not only meaningful learning experiences, but also meaningful life experiences." A2

"Everywhere in our lives ... I integrate such technologies into my life. Especially in house cleaning." A6 "With this technology, all data about people can be easily collected and processed. For example, the follow-up of patients and people around them in the recent COVID-19 outbreak can be managed more effectively with such technologies. In summary, this technology can be used in epidemics, natural disasters, traffic regulation, human tracking, and household chores." A5

"I think there is no end to it. It can be used in almost every field from city planning management to education, from health to tourism." A4

"It will become life itself in all areas of life, from air flights to train rides, from tooth extraction to buying clothes." Al

\section{DISCUSSION, CONCLUSION AND SUGGESTIONS}

Within the scope of this study, the first research question that was directed to the participants and received answers in this direction was on the usability of IoT in traditional learning environments. Data obtained in this context shows that IoT can be used to create smart course materials, smart classrooms, and smart campuses in face-to-face traditional environments. The elements under these main themes indicate that technological tools such as smart pens, highlighters, e-books, smart boards, sensors, interactive libraries, and laboratories can be used in traditional learning environments. Similar to the findings in this study, in the management of smart classes, IoT technology can be used as Interactive Whiteboards, Tablets and Mobile devices, 3-D Printers, eBooks, Student ID, Temperature Sensors, Wireless Door Locks, Attendance Tracking Systems, Security Cameras, and Smart HVAC systems (Gul et al. 2017). Similarly, Biz4intellia (2019), Joshi (2019), and Valois-Chénier (2020) emphasize that IoT-powered smart classes will become widespread in the near future.

Kassab, DeFranco and Laplante (2020) emphasized that smart campuses and remote interactive laboratories will be one of IoT's educational architectural solutions. This view is consistent with the findings obtained within the study. Smart learning materials used in smart classrooms also enable 
students to experience smart learning with IoT. In addition to learning tools such as smart pencil, e-book, highlighter obtained in this study, different learning technologies can be used to increase productivity in education.

Another question of the study is what participants' opinions about the usability of IoT in open and distance learning environments. The data obtained to answer this question indicate that big data and learning analytics will be used more actively. Bakla (2019) stated that teachers can use big data to follow up class participation levels and adapt teaching practices accordingly. Regarding this situation, Burns (2020) mentioned that the big data collected during classroom study could provide more information about the skills and abilities of individual students compared to any standardized test. Based on the idea of big data collection, each student can be individually evaluated and monitored with IoT. Weaker students may be offered a modified curriculum to speed them up. Furthermore, bulk data can guide instructors to make changes to the course based on collective classroom requirements (Qazi, 2019).

Another finding about usability of IoT in open and distance learning environments was that remote laboratories could be established. In line with this finding, Kassab, DeFranco and Laplante (2020) argue that in the context of teaching/classroom use of remote laboratories, IoT is one of the technologies that can be used in an educational sense.

Another finding related with main theme was personalized learning. It was found that IoT can provide personalized learning experiences for open and distance learners. In parallel with this finding, Bagheri and Movahed (2016) stated that data collected from smart devices can be used to provide a more personalized learning experience in real-time. In the context of personalized learning, IoT can identify each student's learning deficiencies and suggest to the instructor how learning materials can be personalized to help each student. With IoT software, the teacher can monitor each student's progress in real-time (Lynch, 2019). In addition to personalized learning, another finding was related with suggestion and decision support systems. In this context, it is stated that thanks to IoT, suggestion and decision support systems that will make educational environments more efficient can be used (Abdel-Basset et al., 2019).

Another finding on the usability of IoT in open and distance learning environments was integration of these environments with innovative technologies. Regarding integration with innovative technologies, IoT integration with augmented reality and virtual reality especially is emphasized in various sources. In IoT-based smart classrooms, students can explore anything such as heavy machinery, interior of the human body, underwater ecosystem (Lynch, 2019). As augmented reality technology becomes more advanced, accessible, and affordable, it will be used in more schools and classrooms. AR and VR environments can be used integrated with IoT to provide interesting and innovative learning opportunities (Igor, 2020).

Wearable technologies, one of the findings of the study, is also one of the technologies that IoT can be used to monitor students' movements, positions, or other information in learning processes. With these wearable devices connected to the internet, it is possible to automatically detect whether a student is at school or send a message about their child's location to parents (Lynch, 2019).

One of the elements that will occur with the use of IoT in open and distance learning environments will be that computer-aided systems communicate with each other. In the context of communication of computer-aided systems with each other theme, Human-machine interaction with IoT is expected to increase (Qazi, 2019). A traditional classroom environment consists of human-to-human interaction. Although this is more intimate, it is not very efficient. As new learning tools, tablets, smartphones, and digital books prepare the education sector for IoT transformation. Human-machine interaction can be very useful in education. With this form of communication, students can learn at their own pace and wherever they want. Interconnected devices such as smart pens, tablets and smartboards can accelerate the distribution of learning materials (Qazi, 2019).

Another research question directed to the participants was what are the benefits of IoT for open and distance learning environments. In this context, participants stated that a more efficient learning environment could be created with IoT. In order for these environments to be more efficient, the 
most underlined element was to profit from time and money. Both students and teachers can save time and money, from monitoring resources and equipment to quick access to programs (Mehta, 2017). Thus, IoT can be used to improve energy efficiency in schools and reduce operating costs. According to Bagheri and Movahed (2016), with IoT integration that helps the organization reduce costs in different ways by automating operations, for example, energy managers can access real-time energy consumption data from campus and easily identify energy waste. In this way, a significant cost reduction can be achieved. Furthermore, smart objects can alert staff to offer service equipment before a problem occurs. In this context, it can be stated that the use of IoT in teaching processes will save time and provide comfort to students and staff by monitoring people, objects, and places in real-time and providing them with feedback. It also reduces the workloads of teachers and other staff and increases their productivity (Valois-Chénier, 2020).

Another finding reached under the relevant main theme was to monitor the development of learners and their device usage. IoT technology can provide reports by monitoring student development and device usage. According to IGOR (2020), IoT networks create opportunities to monitor device usage in the school environment. When students use IoT-connected tablets and laptops, these devices can be programmed to automatically send usage and performance reports directly to teachers. Automatic motion sensors and occupancy indicators can provide information on device and room use, especially in areas such as school libraries or computer labs. Tracking such data allows school staff to observe and report on how students use specific areas and resources. Thus, it can be stated that learning processes will be more efficient and more effective.

It was stated that one of the benefits of IoT for open and distance learning processes will be to increase learners' motivation. According to Valois-Chénier (2020), with interactive and engaging educational content with IoT, students' curiosity levels increase and learning becomes a fun exercise. From this point of view, it can be stated that the performance of learners will increase with IoT. In addition to increasing motivation, it was found that learners' participation and interaction in learning processes will increase with IoT. In parallel with this finding, Joshi (2019) and Ravindra (2018) stated that students who interact with both their teachers, other students, and other IoT-based devices can engage in a more effective learning process. In this context, it can be stated that IoT can help institutions improve the quality of teaching and learning by providing a richer learning experience and understanding of real-time action for students' performance (Bagheri \& Movahed, 2016).

It was also found that one of the benefits of IoT in learning environments is to facilitate follow-up of students and teachers and manage the process. In one of the studies conducted on this subject, Qazi (2019) emphasized that thanks to IoT, student data is delivered instantly to teachers and management and this situation is important in managing the process. With the collected data, students' weaknesses are effectively determined, and teachers can come together in efforts to provide some modules that can be efficient for these students (Valois-Chénier, 2020).

Participants emphasized that one of the most important benefits of IoT is the connection of processes to the automation system. The increase in connected technology will allow teachers to use their time and resources for more personalized teaching, as IoT will automate previously manually executed processes (Mehta, 2017). With IoT report automations, school administrators can create student progress reports, financial planning reports, school management reports in the form of weekly, monthly or annual reports integrated with artificial intelligence (Lynch, 2019).

Another finding on the benefits of IoT was the provision of a suitable learning environment for disabled and disadvantaged groups. In this context, it can be stated that IoT technology should be used to enable disabled and disadvantaged learners to take a more active role in their learning processes. IoT-based intelligent classroom technology enables slow learners to learn at their own pace. IoT devices are also able to convert audio files to text for students with hearing disabilities (Valois-Chénier, 2020). Students with hearing disabilities can wear gloves connected to a laptop or smartphone. These gloves and smartphones can work together to translate sign language into speech. So, educators can better communicate with their students and get feedback on teaching methods. In 
this way, educators can give their students the best possible sign language education (Joshi, 2019). Students with visual impairment may be given special cards that are automatically detected and can inform connected devices to display text in a larger font. Through these advances, IoT can facilitate equal access to education for all students (Mehta, 2017).

Another research question directed to the participants was what are the limitations of IoT for open and distance learning processes. Lack of internet and technological infrastructure and lack of adequate human resources were emphasized as limitations. In this context, the ability to integrate IoT into learning processes is considered one of the most important limitations (Sani, 2019). On the other hand, ALE (2018) emphasized that correct network resources must be provided for proper and efficient operation of the IoT system. Another limitation emphasized by participants was exposure to cyber-attacks. The growth of IoT in education also brings an explosion of cybersecurity threats as the proliferation of sensors and connected devices greatly expands network attack surface. Therefore, it is necessary to provide a secure environment against cyber-attacks and data loss in IoT-based environments (ALE, 2018). By increasing the quality of cybersecurity with IoT, important steps can be taken against cyber-attacks. (Burrell et al., 2020).

One of the most highlighted findings under this main theme has been the issue of personal data protection and privacy violations. Nowadays, concerns about the adoption of IoT are about privacy and security (Sani, 2019). To prevent this, robust technological solutions must be developed by national and international legislators (Aldowah et al., 2017). Therefore, overcoming security issues in IoT devices and services should be a key priority before they are used for educational purposes. The key element of the IoT platform is that it should include efficiency, privacy, and security mechanisms. (Mineraud, Mazhelis, Su \& Tarkoma, 2016). Extra efforts have been made to solve the security problem of IoT infrastructure in higher education. However, there is not any approach to identify commercial risks associated with data breaches yet (Aldowah et al., 2017).

Another element mentioned in the context of limitations of IoT for open and distance learning processes was increase in cost. Information technology hardware can be costly, and it may be necessary to purchase these hardware and software to install IoT infrastructure (Qazi, 2019). In addition to information technology and laboratory fees, most universities do not have a cost strategy for IoT infrastructure (Aldowah, 2017). Based on this point, the inability of institutions to meet the costs that can integrate this technology into processes is considered an obstacle to the widespread use of IoT in learning processes. The inability of institutions to meet the costs of integrating this technology into processes is evaluated as an obstacle to the widespread use of IoT in learning processes.

Another limitation mentioned by participants was the lack of technology literacy. According to Sani (2019), IoT hardware and software can be difficult to manage by novice users. Because IoT applications require remote management of objects and devices, it requires many actions such as turning the device off/on, device/network configuration, firmware/software update, error reduction, monitoring, data collection (Aldowah, 2017). For the effective adoption of IoT, it is necessary to ensure that users have technological literacy.

Based on the participants' answers to the question of what future trends in IoT use may be in learning environments, some findings have been reached. One of the most remarkable finding has been a more reliable assessment process. Considering vital importance of an effective evaluation process in the process of open and distance learning (Master, Uluman and Günal, 2016), increasing reliability of the measurement and evaluation process with technologies such as IoT is important for efficiency of learning process.

Another finding was that it will become easier to access accurate information with emerging technologies such as IoT. Easier access for learners to information that is accurate for them is considered as an element that will increase the efficiency of learning processes.

When the main theme of using IoT outside of learning environments is examined, it was determined that these technologies can be used in almost every aspect of our daily life. The introduction of robots that will help everyday jobs, especially for housewives, is seen as an element that will also 
spread the use of this technology. According to Simoens, Dragone and Saffiotti (2018), there is a new concept called "the Internet of Robotic Things" and describes the integration of robotics and IoT. The entry of IoT into our lives in all areas can also be defined as a situation that will continue to become widespread. This can be considered as an element that will allow the formation of smart cities that will facilitate life. Another important point is that IoT technologies facilitate follow-up of individuals in pandemic and disaster processes. Knowing where individuals are in such situations and being able to communicate with them easily is an important element to take measures in the process.

\section{Suggestions}

It can be proposed to conduct research in different contexts with the participation of experts from different fields by using different research methods on the usability of IoT technology in open and distance learning. By conducting especially experimental studies on the usability of IoT technology in open and distance learning, the effectiveness of IoT can be measured. In this study, open and distance learning experts' views in Turkey were consulted. It can be recommended to organize focus group interviews and Delphi panels by forming an international and widely attended expert list. 


\section{REFERENCES}

Abbasy, M. B., \& Quesada, E. V. (2017). Predictable influence of IoT (Internet of Things) in the higher education. International Journal of Information and Education Technology (IJIET), 7(12), 914-920. doi:10.18178/ ijiet.2017.7.12.995

Abdel-Basset, M., Manogaran, G., Mohamed, M., \& Rushdy, E. (2019). Internet of things in smart education environment: Supportive framework in the decision-making process. Concurrency and Computation, 31(10), e4515. doi:10.1002/cpe.4515

Aldowah, H., Rehman, S. U., Ghazal, S., \& Umar, I. N. (2017). Internet of things in higher education: A study on future learning. Journal of Physics: Conference Series, 892(1), 012017. doi:10.1088/1742-6596/892/1/012017

ALE. (2018). The Internet of Things in Education. Retrieved on 11 August 2020 from https://www.al-enterprise. com/ko-kr/-/media/assets/internet/documents/iot-for-education-solutionbrief-en.pdf

Altınpulluk, H. (2018). Nesnelerin interneti teknolojisinin eğitim ortamlarında kullanımı. Açıköğretim Uygulamaları ve Araştırmaları Dergisi, 4(1), 94-111.

An, N., Wang, J., \& Wang, H. (2018). Research and Practice on Innovative Methods of Ideological and Political Education for College Students Based on Internet of Things+ Technologies. Educational Sciences: Theory and Practice, 18(5).

Bagheri, M., \& Movahed, S. H. (2016). The effect of the Internet of Things (IoT) on education business model. In 2016 12th International Conference on Signal-Image Technology \& Internet-Based Systems (SITIS) (pp. 435-441). IEEE.

Bakla, A. (2019). A critical overview of internet of things in education. Mehmet Akif Ersoy Üniversitesi Ĕgitim Fakültesi Dergisi, (49), 302-327.

Bao, Y. F. (2016). Analysis of the learning evaluation of distance education based on the Internet of Things. World Transactions on Engineering and Technology Education, 14(1), 168-172.

Biz4intellia. (2019). 5 IoT applications in the education industry. Retrieved on 11 August 2020 from https:// www.biz4intellia.com/blog/iot-applications-in-education-industry/

Burns, M. (2020). IoT in education: smart learning environments. Retrieved on 11 August 2020 from https:// www.digitalistmag.com/iot/2019/03/27/iot-in-education-smart-learning-environments-06197356/

Burrell, D. N., Courtney-Dattola, A., Burton, S. L., Nobles, C., Springs, D., \& Dawson, M. E. (2020). Improving the Quality of "The Internet of Things" Instruction in Technology Management, Cybersecurity, and Computer Science. International Journal of Information and Communication Technology Education, 16(2), 59-70. doi:10.4018/IJICTE.2020040105

Cisco. (2014). The cisco connected learning experience strategies for higher education. White Paper. Retrieved on 15 August 2020 from https:/www.cisco.com/c/dam/en_us/solutions/industries/docs/education/learningexperience-whitepaper.pdf

Creswell, J. W. (2003). Research Design: Qualitative, Quantitative and Mixed Methods Approaches. Sage.

Davies, D., Beauchamp, G., Davies, J., \& Price, R. (2020). The potential of the 'Internet of Things' to enhance inquiry in Singapore schools. Research in Science \& Technological Education, 38(4), 484-506. doi:10.1080/0 2635143.2019.1629896

Deng, Z., \& Sang, Q. (2010). The applications and thinking of the Internet of Things in education. Journal of WUXI Institute of Technology, 4.

Gul, S., Asif, M., Ahmad, S., Yasir, M., Majid, M., \& Arshad, M. S. (2017). A survey on role of internet of things in education. IJCSNS, 17(5), 159.

Igor. (2020). Creating smarter schools: benefits and applications of iot in education. Retrieved on 2 September 2020 from https://www.igor-tech.com/news-and-insights/articles/creating-smarter-schools-benefits-andapplications-of-iot-in-education 
Joshi, N. (2019). The growing role of IoT in education. Retrieved on 2 September 2020 from https://www.allerin. $\mathrm{com} / \mathrm{blog} /$ the-growing-role-of-iot-in-education

Juniper Research. (2020). 'Internet of things' connected devices to almost triple to over 38 billion units by 2020. Retrieved on 5 September 2020 from https://www.juniperresearch.com/press/press-releases/iot-connecteddevices-to-triple-to-38-bn-by-2020

Kassab, M., DeFranco, J., \& Laplante, P. (2020). A systematic literature review on Internet of things in education: Benefits and challenges. Journal of Computer Assisted Learning, 36(2), 115-127. doi:10.1111/jcal.12383

Kılınç, H. (2020). Nesnelerin İnterneti. In M. Kesim \& T. V. Yüzer (Eds.), Açık ve Uzaktan Öğrenmenin Teknoloji Boyutu (pp. 165-183). Pegem Akademi. doi:10.14527/9786257052016.07

Kortuem, G., Bandara, A. K., Smith, N., Richards, M., \& Petre, M. (2013). Educating the Internet-of-Things generation. Computer, 46(2), 53-61. doi:10.1109/MC.2012.390

Korzun, D., \& Bogoiavlenskaia, O. (2020). Internet of Things Education for MSc Study in Applied Mathematics and Computer Science. In 2020 26th Conference of Open Innovations Association (FRUCT) (pp. 207-215). IEEE. doi:10.23919/FRUCT48808.2020.9087443

Lynch, M. (2019). The internet of things for education: a brief guide. Retrieved on 5 September 2020 from https://www.thetechedvocate.org/the-internet-of-things-for-education-a-brief-guide/

Markets and Markets'in. (2018). IoT in education market. Retrieved on 5 September 2020 from https://www. marketsandmarkets.com/Market-Reports/iot-education-market-115520843.html

Mehta, A. (2017). The potential of the iot in education. Retrieved on 5 September from https://www. convergetechmedia.com/potential-iot-education/

Mertala, P. (2020). Young children's perceptions of ubiquitous computing and the Internet of Things. British Journal of Educational Technology, 51(1), 84-102. doi:10.1111/bjet.12821

Miles, B. M., \& Huberman, A. M. (1994). Qualitative data analysis: An expanded source book (2nd ed.). Sage Publications.

Mineraud, J., Mazhelis, O., Su, X., \& Tarkoma, S. (2016). A gap analysis of Internet-of-Things platforms. Computer Communications, 89, 5-16. doi:10.1016/j.comcom.2016.03.015

Qazi, A. (2019). How will Iot change the education sphere? Retrieved on 5 September from https://www. emergingedtech.com/2019/05/how-will-iot-change-impact-education/

Ravindra, S. (2018). Role of IoT in education. Retrieved on 5 September 2020 from https://www.kdnuggets. com/2018/04/role-iot-education.html

Sani, R. M. (2019). Adopting Internet of Things for higher education. In Redesigning Higher Education Initiatives for Industry 4.0 (pp. 23-40). IGI Global. doi:10.4018/978-1-5225-7832-1.ch002

Shaikh, H., Khan, M. S., Mahar, Z. A., Anwar, M., Raza, A., \& Shah, A. (2019). A Conceptual Framework for Determining Acceptance of Internet of Things (IoT) in Higher Education Institutions of Pakistan. In 2019 International Conference on Information Science and Communication Technology (ICISCT) (pp. 1-5). IEEE. doi:10.1109/CISCT.2019.8777431

Shyr, W. J., Zeng, L. W., Lin, C. K., Lin, C. M., \& Hsieh, W. Y. (2018). Application of an energy management system via the internet of things on a university campus. Eurasia Journal of Mathematics, Science and Technology Education, 14(5), 1759-1766. doi:10.12973/ejmste/80790

Simoens, P., Dragone, M., \& Saffiotti, A. (2018). The Internet of Robotic Things: A review of concept, added value and applications. International Journal of Advanced Robotic Systems, 15(1), 1729881418759424. doi: $10.1177 / 1729881418759424$

Songsom, N., Nilsook, P., Wannapiroon, P., Fung, C. C., \& Wong, K. W. (2019). System design of a student relationship management system using the internet of things to collect the digital footprint. International Journel of Emerging Technologies in Learning, 14(23), 125-140. doi:10.3991/ijet.v14i23.11066 
Sun, Z., Xing, X., Wang, T., Lv, Z., \& Yan, B. (2019). An optimized clustering communication protocol based on intelligent computing in information-centric Internet of Things. IEEE Access: Practical Innovations, Open Solutions, 7, 28238-28249. doi:10.1109/ACCESS.2019.2896250

Tobarra, L., Robles-Gómez, A., Pastor, R., Hernández, R., Cano, J., \& López, D. (2019). Web of Things Platforms for Distance Learning Scenarios in Computer Science Disciplines: A Practical Approach. Technologies, 7(1), 17. doi:10.3390/technologies 7010017

Tutorials Point. (2020). Internet of things - education applications. Retrieved on 9 September 2020 from https:// www.tutorialspoint.com/internet_of_things/internet_of_things_education_applications.htm

Usta, G., Günal, Y., \& Uluman, M. (2016). Views of Instructors and Students Regarding Online Measurement and Evaluation Applications. Humaniora, 7(3), 307-314. doi:10.21512/humaniora.v7i3.3583

Valois-Chénier, M. (2020). IoT in education industry- smart classroom technology. Retrieved on 9 September 2020 from https://www.chapter247.com/blog/iot-in-education-industry-smart-classroom-technology/

Yang, Y., \& Yu, K. (2016). Construction of distance education classroom in architecture specialty based on internet of things technology. International Journal of Emerging Technologies in Learning, 11(5), 56. doi:10.3991/ ijet.v11i05.5695

Yeh, J. H. J., Bartholio, C., Shackleton, E., Costello, L., Perera, M., Yeh, K., \& Yeh, C. (2020). Environmentally Embedded Internet-of-Things for Secondary and Higher Education. In 2020 3rd International Conference on Information and Computer Technologies (ICICT) (pp. 543-547). IEEE.

Yıldırım, A., \& Şimşek, H. (2011). Sosyal Bilimlerde Nitel Araştırma Yöntemleri (8 ${ }^{\text {th }}$ ed.). Ankara: Seçkin Yayınları.

Hakan Altınpulluk is an Assistant Professor Dr. in Distance Education at the College of Open Education of Anadolu University, Turkey. He undertook undergraduate studies in the field of Computer Education and Instructional Technologies (CEIT) between the years of 2005-2009 at Anadolu University. Hakan Altınpulluk continues to work in the field of Open and Distance Education, Augmented Reality, Virtual Reality, Mobile Learning, Mobile Health, Massive Open Online Courses, Learning Management Systems, Open Educational Resources, Personal Learning Environments, and E-Learning Systems. 